\title{
Switchable double band-notch ultra wideband monopole antenna
}

\author{
Mohammad Naser-Moghadasi ${ }^{a}$, Sajjad Faraji Gotolo ${ }^{\text {b) }}$ \\ and Nima.Bayat Maku ${ }^{\mathrm{c}}$ \\ Faculty of Eng., Science and Research Branch, Islamic Azad University, \\ Tehran-IRAN \\ a)mn.moghaddasi@srbiau.ac.ir \\ b)S.Faraji_telecom@yahoo.com \\ c) N.Bayat_maku@ieee.org
}

\begin{abstract}
In this paper, a novel small dual band-notch ultra-wideband planar monopole antenna with switchable functions is presented. Impedance bandwidth of the proposed antenna is approximately $136 \%$ with $\mathrm{VSWR}<2$ in the frequency range of $2.2 \mathrm{GHz}-11.6 \mathrm{GHz}$. By inserting a U-shaped slot and SES structures on the patch of antenna, the dual band-notch characteristics are obtainable. The technique of on/off switching of notched bands is based on mounting three pairs of PIN diodes at a certain locations on antenna structure.
\end{abstract}

Keywords: ultra-wideband antenna, dual band-notch

Classification: Microwave and millimeter wave devices, circuits, and systems

\section{References}

[1] FCC, First Report and Order on Ultra Wide Band Technology, 2002.

[2] Y. F. Weng, S. W. Cheung, and T. I. Yuk, "Ultra-wide band antenna using CPW resonators for dual- band notched characteristic," IEEE, Wireless Communications 83 Signal Processing, pag., pp. 1-4, Nov. 2009.

[3] P. Horng, W. S. Chen, C. H. Huang, "Dual wideband printed monopole antenna for WLAN/WIMAX applications," IEEE Antenna Wireless Propag. Lett., vol. 6, pp. 149-151, 2007.

[4] S.-J. Kim, J.-W. Baik, and Y.-S. Kim, "A CPW-Fed UWB Monopole Antenna with Switchable Notch-band," IEEE, Antennas and Propagation Society, vol. 6, pp. 4641-4644, 2007.

[5] N. Behdad and K. Sarabandi, "A Varactor-Tuned Dual-Band Slot Antenna," IEEE Trans. Antennas Propag., vol. 54, no. 2, 2006.

[6] E. Antonio, M. Cabedo, M. Ferrando, and M. Baquero, "Novel UWB antennas with switchable and tunable band-notched behavior," IEEE, Antennas and Propagation Society, vol. 6, pp. 693-696, 2007. 


\section{Introduction}

Ultra-wideband (UWB) is a radio technology that can be used at very low energy levels for short-range high-bandwidth communications by using a large portion of radio spectrum which has been widely used in wide variety of applications [1].

Regulatory setting of Federal Communications Commission (FCC) approved the frequency range of $3.1 \sim 10.6 \mathrm{GHz}$ for commercial use of UWB systems in 2002.

Some advantages of UWB antennas like such small size, Omni-directional pattern, low group delay, [3] constant gain and linear phase response, [4] catch the attention of researcher to more study of them.

The existing some narrow band wireless systems such as: Wireless Local Area Network (WLAN) using IEEE 802/11a protocol which is operating over 5.15-5.825 GHz and worldwide interoperability for microwave access (WiMAX) using the frequency band of $3.15-3.85 \mathrm{GHz}$, can cause the performance degradation of UWB systems because of interference between them. [5] In order to overcome this problem, various UWB antennas have been designed to omit the undesirable bands causing interference with other systems. In this way, different kinds of techniques have been utilized to reach the desirable performance of UWB systems without any distortion from other narrow-band devices $[2,6]$.

In this paper, two kinds of techniques are used to achieve the elimination of two undesirable bands from UWB operations. Also, another inventive technique by using PIN diodes is introduced for on/off switching of rejected bands.

\section{Antenna design}

Figure 1a and $1 \mathrm{~b}$ show the physical geometry and constructed prototype of the suggested antenna consisting of a simple U-shaped slot with a microstrip fed line and two Square Earrings-Shaped (SES) resonant structures. This antenna is designed and constructed to operate on frequency range of 2.2 to 11.6 GHz with two notched bands which are obtained by adding SES on two sides of the patch and U-shaped slot in the middle.

The antenna is fabricated on RT/Duroide 5880 substrate with thickness of $1.6 \mathrm{~mm}$ and relative dielectric permittivity of $\varepsilon_{r}=2.33$ and low dielectric $\operatorname{losses}(\tan \delta=0.012)$. Furthermore, the proposed antenna has a small size of the $18 \times 21, \mathrm{~mm}^{2}$ and the optimum width of the microstrip fed line is fixed at $2 \mathrm{~mm}$ to achieve characteristic impedance of $50 \Omega$.

In this structure, by embedding a half-wavelength U-shaped slot into the radiating patch of the antenna, the first feature of band notching characteristics appeared which strongly eliminate the frequency band pertinent to WiMAX operations from wide-band operations of proposed antenna. The effects of U-shaped slot and its dimension's variations are illustrated in next section.

By applying SES structures in both sides of the patch, furthermore the 


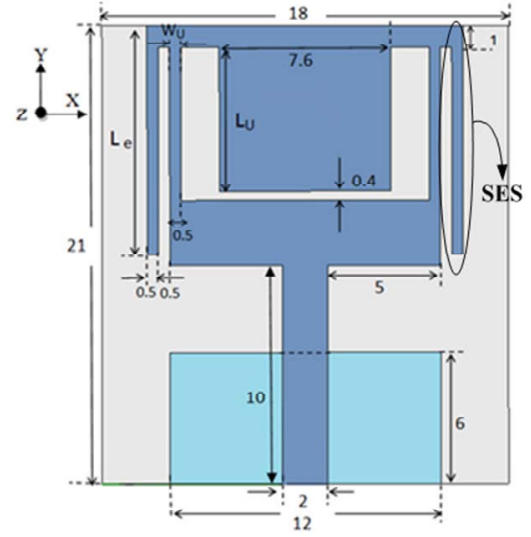

(a)

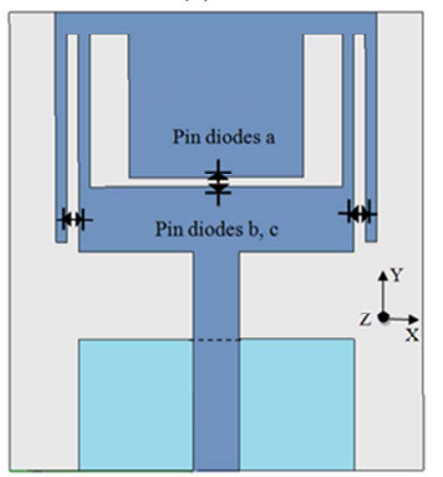

(c)

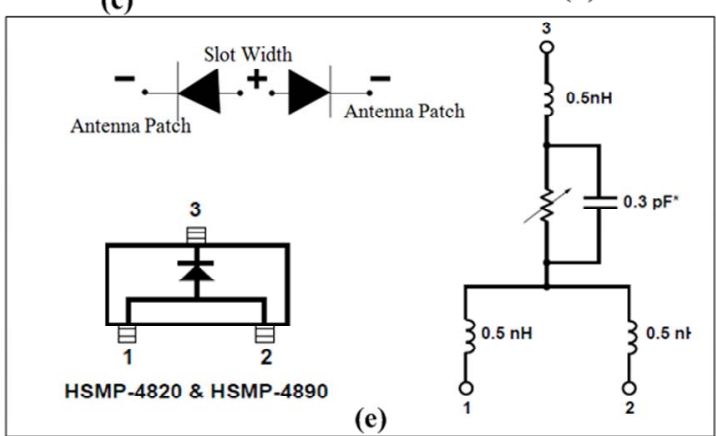

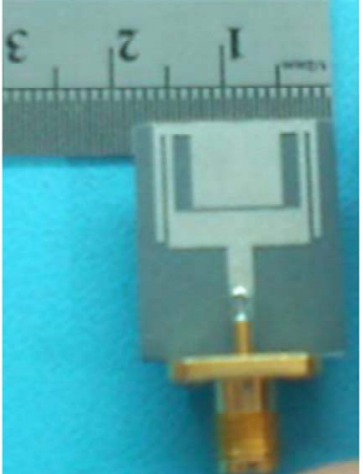

(b)

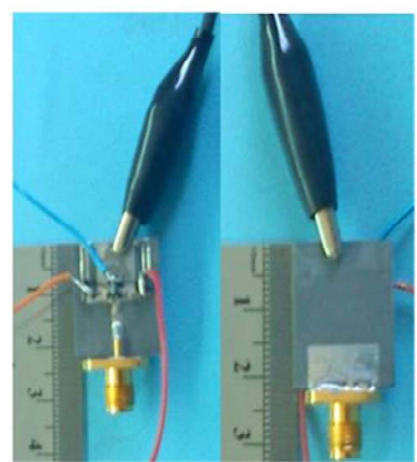

(d)

Fig. 1. (a) Geometry of the proposed antenna with definitions of its physical parameters in both front and back views (dimensions in $\mathrm{mm}$ ), (b) prototype of an UWB dual band-notch antenna without pin diodes in front view, (c) the location of PIN diodes mounted on antenna board, (d) the prototype of proposed antenna with mounted PIN diodes, (e) the equivalent circuit of PIN diodes and its mounting details on the antenna board.

electromagnetic fields are eliminated regarding to Lenses principle and reverse surface current flows between SES structures and radiation patch. So, the frequency band of WLAN operations which is another interfering band of UWB systems is eliminated.

The simulation and measurement results related to different size of SES's arm on antenna operations are depicted in the following section.

Figure 1c, 1d delineates other new design of UWB antenna with recon- 
figurable characteristic. In this stage of antenna design, three pairs of PIN diodes are mounted on antenna structure to add on/off switching of notched bands to our proposed antenna. The PIN diodes (a) on thin part of U-shaped slot are for on/off switching of first rejected band of WiMAX operations. Also, the PIN diodes (b) and (c) which are mounted between SES's arms and main patch of the antenna are for on/off switching of WLAN operations band. The type of PIN diodes is HSMP-4890 that its schematic and equivalent circuit is shown in figure 1e. In the simulation process, the PIN diodes are modeled as a lumped element capacitor in open state and as a lumped element resistor in shorted state in order to take the non-ideal behavior of the diode into account.

\section{Simulation and measurement results}

The simulation processes of proposed antenna are done by Ansoft's highfrequency structure simulator (HFSS), and the measurement results are obtained by using Agilent's Network Analyzer E8361c.

As a first investigation, the simulation and measurement results of voltage Standing Wave Ratio (VSWR) response of the UWB antenna with notched bands with central frequencies of $3.5 \mathrm{GHz}$ and $5.5 \mathrm{GHz}$ are presented in figure 2a. The following illustrations describe the simulation results of changing the dimensions of U-shaped and SES structures. Figures $2 \mathrm{~b}$ and $2 \mathrm{c}$ depict the VSWR results for different values of $\left(\mathrm{L}_{\mathrm{U}}\right)$ and $\left(\mathrm{W}_{\mathrm{U}}\right)$ of $\mathrm{U}$-shaped slot and figure $2 d$ shows the effects of arm's length of SES structure $\left(L_{e}\right)$ on antenna's performance. It can be easily seen that by varying these parameters, the central frequencies of notched bands can be easily changed and adapted with desired frequencies. However, the optimum values of critical dimensions of the antenna for accurate eliminating the frequencies of WiMAX and WLAN operation are: $\mathrm{L}_{\mathrm{e}}=6.6 \mathrm{~mm}, \mathrm{~W}_{\mathrm{e}}=0.5 \mathrm{~mm}$ and $\mathrm{L}_{\mathrm{e}}=10.5 \mathrm{~mm}$. It should be noted that the effect of mutual coupling between first and second notched bands of the antenna is infinitesimal.

In continuance of our researches, for reaching the switchable function of antenna's notched bands, three pairs of PIN diodes are mounted on the proposed UWB dual band-notched planar monopole antenna. All of the PIN diodes are the same and are modeled in accordance with data sheets, namely, as a resistor of $2.5 \Omega$ in the on state and as a capacitor of $0.8 \mathrm{pF}$ in the off state. Also, they are activated by exerting $5 \mathrm{~V}$ of biasing voltage for on/off switching of notched bands. Figures $2 \mathrm{e}, 2 \mathrm{~g}$, and $2 \mathrm{f}$ clearly illustrate the VSWR responses of the antenna in different states of mounted PIN diodes.

The normalized radiation patterns of the proposed antenna at four different frequencies are presented in figure 3 . The antenna's patterns are simulated when all of the PIN diodes are in off state and the antenna acts in its main operation as an UWB antenna with two separated notched bands. In the second radiating pattern which is in $4.5 \mathrm{GHz}$ between two notched bands, the antenna shows averagely $16.5 \mathrm{~dB}$ difference between co- and crosspolarization levels for both $\mathrm{H}$-and E-plane. 


\section{Conclusion}

A compact UWB antenna with two switchable band notching characteristic was introduced. The frequency-notches were obtained by implementing a U-shaped slot in the radiating patch and SES structures. The central frequencies of obtained notched bands can completely sweep all frequencies of WiMAX and WLAN bands. Also, the feature of on/off switching of notched bands are added to antenna by mounting three pair of PIN diodes on the antenna structures, so the desirable band notching feature with favorable

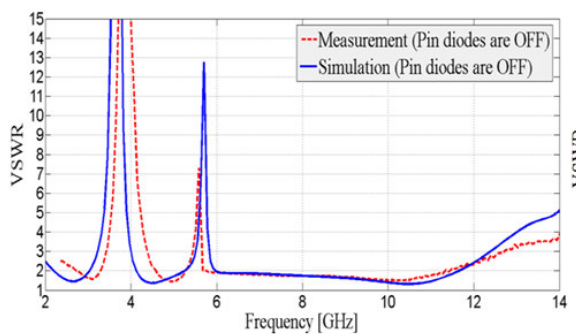

(a)

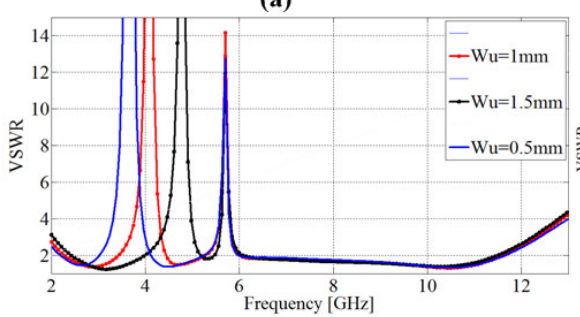

(c)

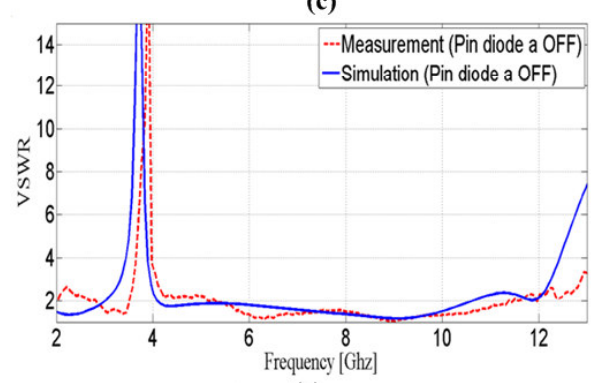

(e)

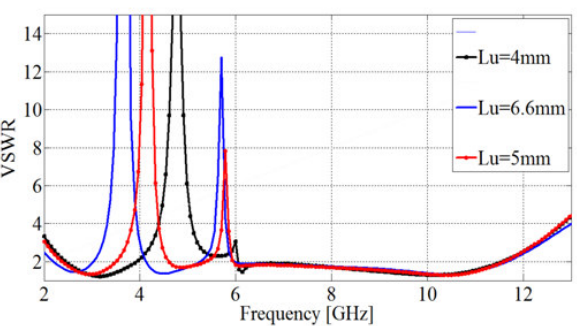

(b)

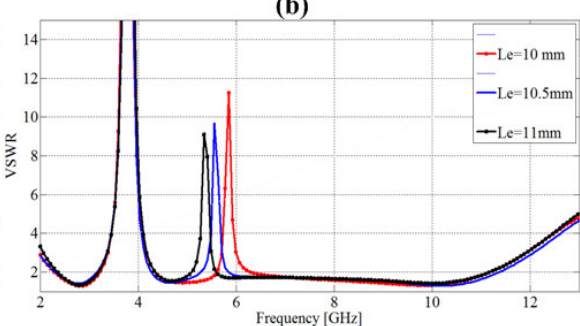

(d)

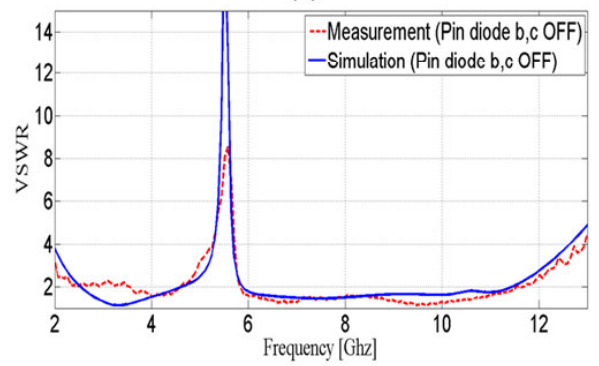

(f)

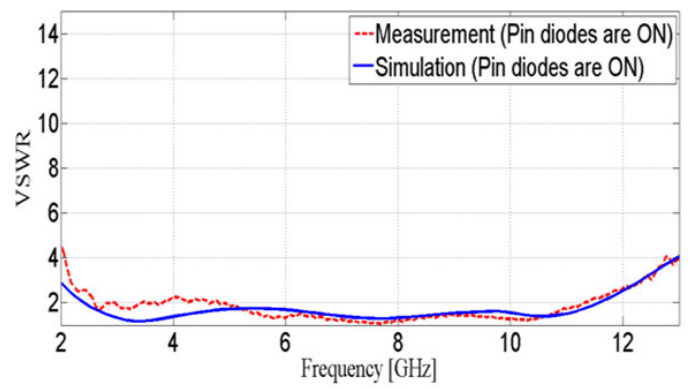

(g)

Fig. 2. (a) VSWR of dual band-notched UWB monopole antenna, VWSR responses dual band-notched UWB monopole antenna by changing values of: (b) $\mathrm{Lu}$, (c) Wu, (d) Le, VSWR response of UWB band-notch on/off switching antenna when (e) PIN diodes $\{b, c\}$ are at ON state, (f) PIN diodes $\{\mathrm{a}\}$ are at $\mathrm{ON}$ state, $(\mathrm{g})$ all of PIN diodes are $\mathrm{ON}$ state. 

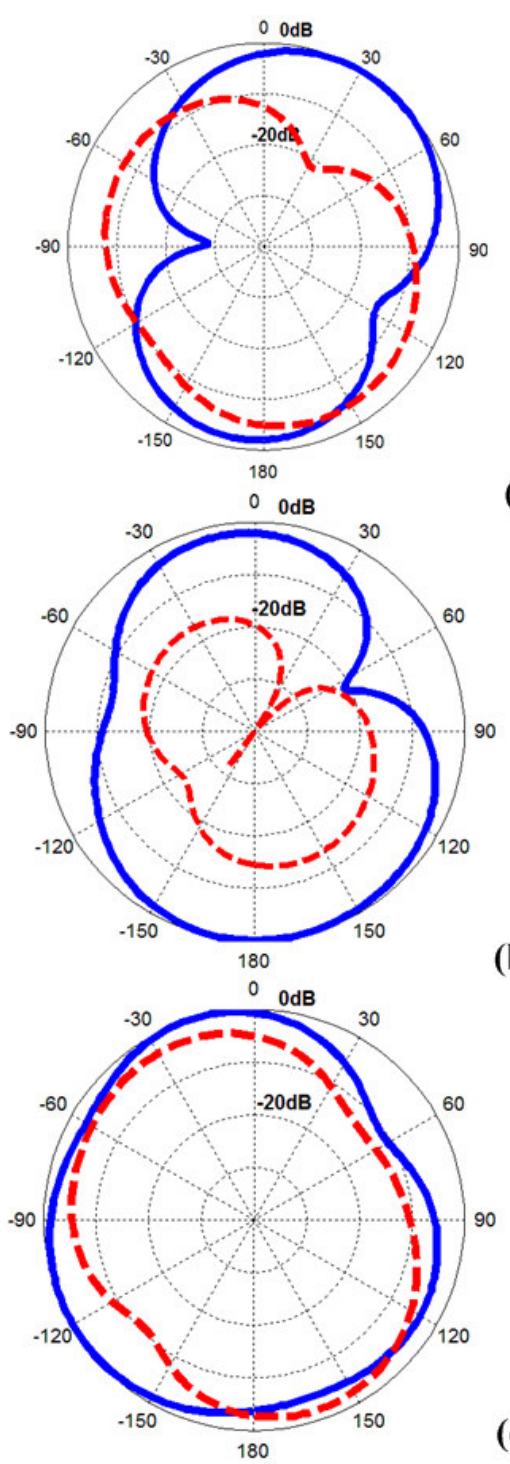

(b)

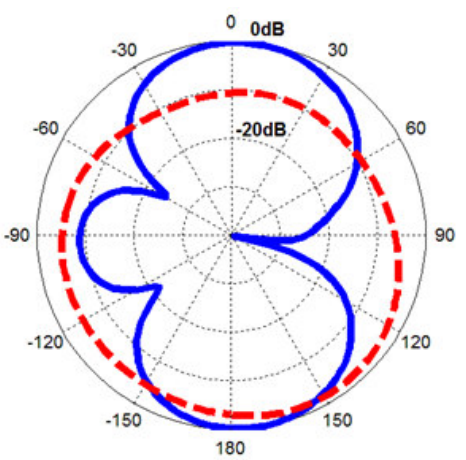

(a)
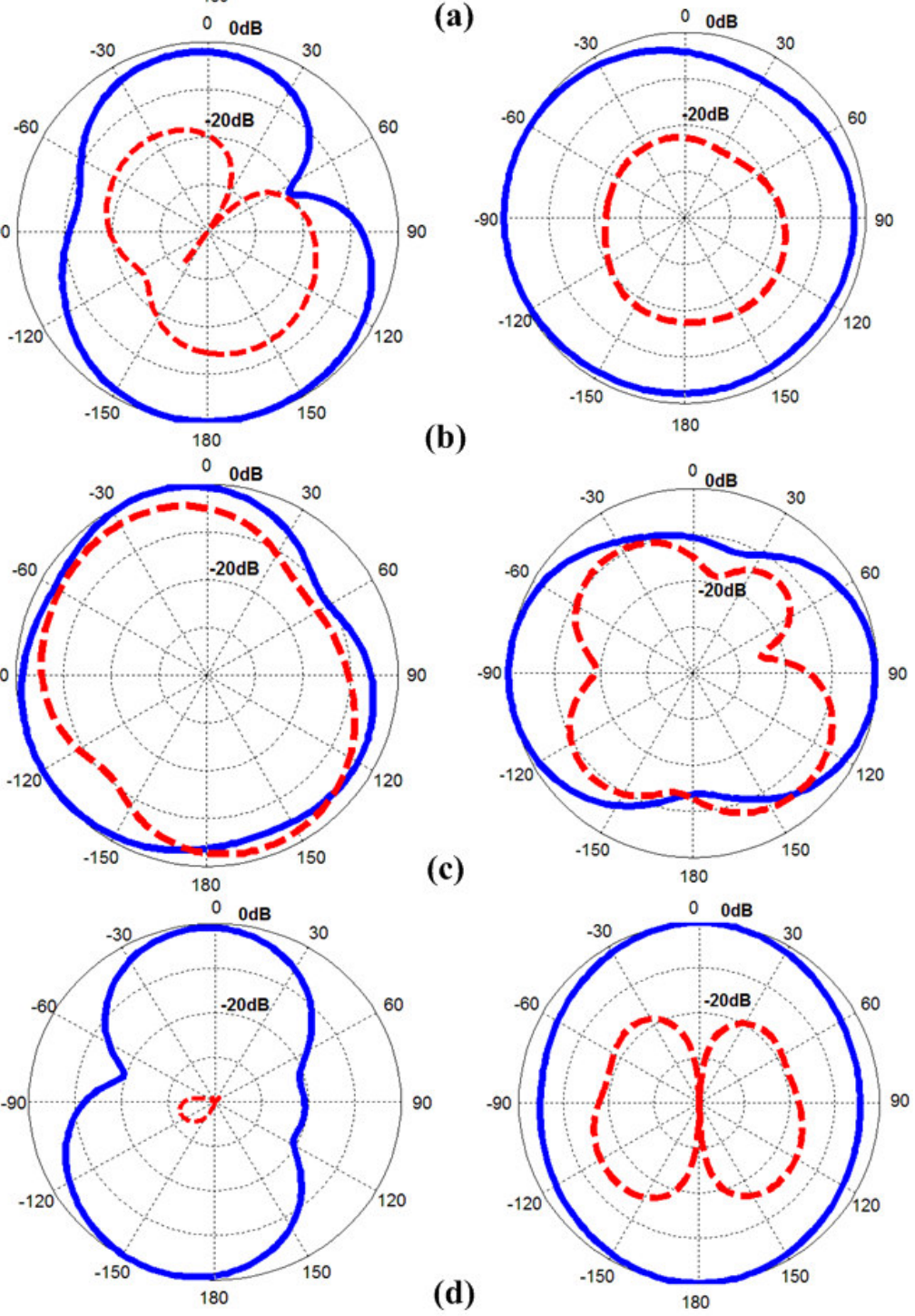

E-Plane

(d)

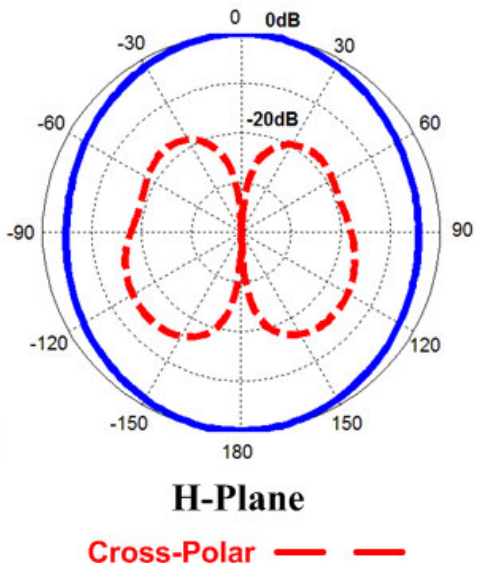

Fig. 3. E-Plane and H-plane of radiation patterns of proposed antenna, (a) at $3.5 \mathrm{GHz}$ (central frequency of first notched band), (b) at $4.5 \mathrm{GHz}$ (antenna operating frequency between first and second notched band), (c) at $5.5 \mathrm{GHz}$ (central frequency of second notched band (d) at $9 \mathrm{GHz}$ 
central frequency can be obtained.

The proposed antenna has a compact size of $18 \times 21 \mathrm{~mm}^{2}$ and provides Omni-directional radiation pattern across the entire UWB bandwidth making it suitable for UWB applications and next generation communication systems. 